\title{
Skin Blood Flowmotion and Microvascular Reactivity Investigation in Hypercholesterolemic Patients Without Clinically Manifest Arterial Diseases
}

\author{
M. ROSSI, A. CARPI ${ }^{1}$, C. DI MARIA, F. FRANZONI, F. GALETTA, G. SANTORO \\ Department of Internal Medicine and ${ }^{1}$ Department of Reproduction and Ageing, University of Pisa, \\ Pisa, Italy
}

Received July 12, 2007

Accepted October 23, 2007

On-line January 17, 2008

\section{Summary}

Fourier spectral analysis of forearm skin laser Doppler flowmetry (LDF) signal was performed in fifteen hypercholesterolemic patients (HP), without clinically manifest arterial diseases, and in fifteen age-matched healthy control subjects (CS), in order to investigate skin blood flowmotion (SBF). The LDF frequency intervals studied were: $0.01-1.6 \mathrm{~Hz}$ total spectrum, as well as 0.01-0.02 Hz (endothelial), 0.02-0.06 Hz (sympathetic), 0.06-0.2 $\mathrm{Hz}$ (myogenic), $0.2-0.6 \mathrm{~Hz}$ (respiratory) and $0.6-1.6 \mathrm{~Hz}$ (cardiac). Skin microvascular reactivity (MVR) to acetylcholine (ACh) and to sodium nitroprusside (SNP) iontophoresis was also investigated. HP showed a lower post-ACh increase in power spectral density (PSD) of the $0.01-0.02 \mathrm{~Hz}$ SBF subinterval compared to CS $\left(1.80 \pm 1.73 \mathrm{PU}^{2} / \mathrm{Hz}\right.$ vs $3.59 \pm 1.78 \mathrm{PU}^{2} / \mathrm{Hz}$, respectively; $\left.\mathrm{p}<0.005\right)$, while they did not differ in MVR from CS. In eleven HP the 0.01$0.02 \mathrm{~Hz}$ SBF subinterval showed a higher post-ACh PSD increase near to the statistical significance after 10 weeks of rosuvastatin therapy (10 mg/day) compared to pretreatment test $(3.04 \pm 2.95$ $\mathrm{PU}^{2} / \mathrm{Hz}$ vs $\left.1.91 \pm 1.94 \mathrm{PU}^{2} / \mathrm{Hz} ; \mathrm{p}=0.07\right)$. The blunted post-ACh increase in PSD of the $0.01-0.02 \mathrm{~Hz}$ SBF subinterval in HP suggests a skin endothelial dysfunction in these patients. This SBF abnormality showed a tendency to improve after rosuvastatin therapy in eleven treated patients.

\section{Key words}

Hypercholesterolemia - Endothelial function - Laser Doppler flowmetry - Flowmotion - Spectral Fourier analysis • Acetylcholine $\bullet$ Sodium nitroprusside

\section{Corresponding author}

M. Rossi, Dipartimento di Medicina Interna, Università degli Studi di Pisa, Via Roma 67, 56100 Pisa, Italia. Fax +50.553414. E-mail: mrossi@int.med.unipi.it

\section{Introduction}

A large number of studies demonstrated endothelial dysfunction of large arteries in hypercholesterolemic patients and suggested that this abnormality is the principal mechanism responsible for the atherosclerotic damage and cardiovascular risk in these patients (Manninen et al. 1992, Vogel et al. 1999, Stein et al. 2001, Davignon and Ganz 2004). More recently, studies based on laser Doppler flowmetry (LDF) investigated skin microvascular reactivity to the endothelial-dependent vasodilator acetylcholine (ACh) (Khan et al. 1999, Binggeli et al. 2003), as well as to ischemic or thermal stimuli (Štulc et al. 2003), in hypercholesterolemic patients. The interest for the study of microvascular reactivity in hypercholesterolemic patients arises from the recently suggested hypothesis that skin microvascular function can mirror the state of microcirculation in other microvascular beds, including cardiac muscle (Jung et al. 2001, Shamin-Uizzaman et al. 2002). Using the above mentioned method, a blunted skin vasodilator response to $\mathrm{ACh}$, which is consistent with endothelial dysfunction, has been found in hypercholesterolemic patients with manifest coronary artery disease (Khan et al. 1999), while a preserved skin vasoreactivity to ACh has been observed in hypercholesterolemic patients without manifest vasculopatic state (Khan et al. 1999), indicating a preserved endothelial function in these patients. Moreover, a preserved skin microvascular reactivity to ischemic and thermal stimuli was found in hypercholesterolemic patients without coronary artery disease (Štulc et al. 2003), However, no studies in 
hypercholesterolemic patients explored the skin blood flow oscillation (so called flowmotion), which has been demonstrated to be in part related to the rhythmic contraction and dilation of skin arterioles (so called vasomotion) (Colantuoni et al. 1984, 1994).

Vasomotion, and the consequent skin blood flowmotion (SBF), has been demonstrated to be due to different mechanisms such as the endothelial activity and the spontaneous myogenic activity of the microvascular wall (Kvernmo et al. 1999, Kvandal et al. 2003). The efficiency of these two specific vasomotion mechanisms can be indirectly evaluated by investigating SBF by the spectral analysis of the skin LDF signal (Stefanovska and Kroselj 1997, Stefanovska et al. 1999, Kvernmo et al. 1999, Rossi et al. 2004, 2006). Five different frequency subintervals have been described within the 0.01-1.6 Hz SBF total spectrum in these studies (Stefanovska and Kroselj 1997, Stefanovska et al. 1999, Kvernmo et al. 1999, Rossi et al. 2004, 2006). Two of them, the SBF frequency subinterval of $0.01-0.02 \mathrm{~Hz}$ and the SBF frequency subinterval of $0.06-0.2 \mathrm{~Hz}$, have been showed to be related to the endothelial-dependent and the myogenic-dependent vasomotion, respectively (Stefanovska et al. 1999, Kvernmo et al. 1999). The SBF frequency subinterval of 0.02-0.06 Hz has been attributed to the local sympathetic activity (Stauss et al. 1998), and finally the SBF frequency subintervals of 0.2-0.6 Hz and of $0.6-1.6 \mathrm{~Hz}$ have been considered due to the transmission to the skin microcirculation of the central hemodynamic modifications synchronous with respiratory (Bollinger et al. 1993) and heart activity (Stefanovska et al. 1997), respectively.

The aims of our study were 1) to study the SBF in hypercholesterolemic patients without clinically manifest arterial diseases in order to investigate skin microvascular endothelial function in these patients, and 2) to evaluate possible changes of SBF in the same patients following rosuvastatin therapy.

\section{Methods}

\section{Subjects}

Fifteen patients affected by hypercholesterolemia were selected from patients who underwent cardiovascular check during the last year in our outpatient clinic. Eligible were patients over 18 years old, with LDL-cholesterol serum levels above $140 \mathrm{mg} / \mathrm{dl}$, never treated with lipid-lowering medication. Patients suffering from diabetes mellitus, arterial hypertension, chronic renal or heart failure, and with clinical evidence of lower limb vascular disease, coronary or cerebral artery disease were excluded, as well as smokers. Fifteen normocholesterolemic (with LDL-cholesterol serum levels below $100 \mathrm{mg} / \mathrm{dl}$ ) normotensive, non-smoker healthy subjects, age-matched with the hypercholesterolemic patients, were recruited among companions of outpatients referring to our clinic, to form control group. Table 1 shows the clinical and laboratory characteristics of 15 hypercholesterolemic patients and 15 control subjects recruited for the study. Hypercholesterolemic patients showed significantly more elevated total cholesterol $(\mathrm{p}<0.005)$ and LDL-cholesterol serum levels $(p<0.005)$ as well as higher diastolic blood pressure values $(p<0.05)$ than control subjects. No significant difference was observed in systolic blood pressure, as well as in respiratory and heart rate between the studied groups. All recruited subjects gave their consent to take part in the study, which was approved by the local Department Committee.

\section{Skin blood flow measurement}

Skin blood flow was measured in conventional perfusion units (PU: $1 \mathrm{PU}=10 \mathrm{mV}$ ) by means of a LDF apparatus (Periflux PF4001, Perimed, Järfälla, Sweden), equipped with a non-heated probe (PF408). The laser characteristics were: $780 \mathrm{~nm}$ wavelength, $10 \mathrm{~Hz}-19 \mathrm{KHz}$ bandwidth, $0.1 \mathrm{~s}$ time constant, $32 \mathrm{~Hz}$ sampling frequency. Calibration was performed before each test session by a specific device (Perimed, Järfälla, Sweden) containing colloidal latex particles whose Brownian motion provides the standard values. The LDF signal has been recorded continuously by an interfaced computer (Acer, Travelmate 202 T) equipped with Perisoft dedicated software.

\section{Acetylcholine and sodium nitroprusside iontophoresis}

Acetylcholine (ACh) and sodium nitroprusside (SNP) iontophoresis was performed as previously described (Morris et al. 1995). A battery-powered iontophoresis controller (PeriIont 328, Perimed, Järfälla, Sweden), equipped with a drug delivery electrode (PF 383, Perimed, Järfälla, Sweden) was used for delivering ACh or SNP to the skin. The drug delivery electrode was connected to the LDF apparatus in order to register the blood flow before and during iontophoresis. An indifferent electrode (PF 384, Perimed, Järfälla, Sweden), was used to provide the current needed for ACh and SNP delivery. 
Each subject avoided food, drugs, tobacco, alcohol, coffee or tea $10 \mathrm{~h}$ prior to the test and had $20 \mathrm{~min}$ of acclimatization in supine position before the test. Room temperature was between $22-24{ }^{\circ} \mathrm{C}$.

Before the examination, a drug delivery electrode was filled with $0.05 \mathrm{ml}$ of $1 \%$ ACh solution and then attached to the dorsal aspect of the third right finger by double-sided adhesive disc. The indifferent electrode was attached on the dorsal aspect of the right hand. ACh was then delivered to the skin by means of an anodal current: nine pulses $(0.1 \mathrm{~mA}$ for $20 \mathrm{~s}$ each) with a $60 \mathrm{~s}$ interval between pulses. After ACh iontophoresis, a drug delivery electrode, previously filled with $0.05 \mathrm{ml}$ of $1 \%$ SNP solution, was attached to the dorsal aspect of the third left finger by a double-sided adhesive disc. The indifferent electrode was attached on the dorsal aspect of the left hand. SNP was then delivered to the skin by means of a cathodal current: seven pulses $(0.2 \mathrm{~mA}$ for $20 \mathrm{~s}$ each) with a $180 \mathrm{~s}$ interval between one to the other. Maximal skin blood flow reached during ACh or SNP iontophoresis was measured in PU. The maximal hyperemic response during ACh or to SNP iontophoresis was also expressed as maximal percentage change from baseline.

\section{Skin blood flowmotion investigation}

Skin blood flowmotion was investigated by means of spectral analysis of the skin LDF signal. For the spectral analysis, as in previous studies (Serné et al. 2002, Rossi et al. 2004, 2006) we used a Perisoft dedicated software (Perimed, Järfälla, Sweden). This software measures in $\mathrm{PU}^{2} / \mathrm{Hz}$ the power spectral density (PSD) of LDF signal, using the basic Fast Fourier Transform algorithm. In this algorithm the beginning and the end of the signal are attenuated by means of a windowing "Parzen" function to avoid the well known "leakage phenomenon" (frequency components in the spectra "leaking" into other frequencies). In the windowing "Parzen" function, a short-time Fourier transform, with a different window length for each frequency interval, was used. The frequency interval from 0.01 to $1.6 \mathrm{~Hz}$ was divided into five subintervals: 0.01-0.02 Hz (endothelial activity), 0.02-0.06 Hz (sympathetic activity), 0.06-0.2 $\mathrm{Hz}$ (vascular myogenic activity), $0.2-0.6 \mathrm{~Hz}$ (respiratory activity) and $0.6-1.6 \mathrm{~Hz}$ (heart activity). The PSD in a definite frequency subinterval has been calculated as the highest PSD in that subinterval. PSD of the $0.01-1.6 \mathrm{~Hz}$ SBF total spectrum was obtained by the sum of the PSD of the five SBF subinterval considered.

Using the above described method, the spectral analysis was performed on the skin LDF tracing registered during $10 \mathrm{~min}$ before $\mathrm{ACh}$ iontophoresis and on the skin LDF tracing registered during the whole duration of $\mathrm{ACh}$ iontophoresis procedure. The post- $\mathrm{ACh}$ iontophoresis change in PSD for each SBF subinterval considered was expressed as difference between the PSD value reached during $\mathrm{ACh}$ iontophoresis and the baseline PSD value of that subinterval. Similarly the post-ACh iontophoresis change in PSD of SBF total spectrum was expressed.

\section{Lipid-lowering intervention}

Hypercholesterolemic patients were treated with rosuvastatin, $10 \mathrm{mg}$ daily for 10 -weeks, starting the treatment in the day of LDF-iontophoresis test. The day after the last rosuvastatin assumption hypercholesterolemic patients underwent a second LDFiontophoresis test.

\section{Laboratory measurements}

The standard biochemical tests were performed in the day before the beginning of rosuvastatin therapy and in the last day of rosuvastatin therapy by automated analyzer methods.

\section{Statistical analysis}

Results were expressed as mean $\pm \mathrm{SD}$ or as mean \pm SEM when specified. Student's $t$ test for paired data was used to compare basal LDF blood flow values and maximal LDF blood flow values following ACh or SNP iontophoresis obtained in each group, as well as LDF blood flow values and laboratory parameter values measured before and after rosuvastatin therapy in hypercholesterolemic patients. Student's t test for non paired data was used to compare LDF blood flow values obtained in hypercholesterolemic patients and control subjects.

Wilcoxon test for non-paired data was used to compare PSD values obtained in the two studied groups. Wilcoxon test for paired data was used to compare PSD values obtained at baseline and during $\mathrm{ACh}$ iontophoresis in each group of subjects, as well as PSD values obtained before and after rosuvastatin therapy in hypercholesterolemic patients. When Wilcoxon test was used, the $\mathrm{p}$ value was corrected by means of Bonferroni method. A $p<0.05$ value was considered as statistically significant. 

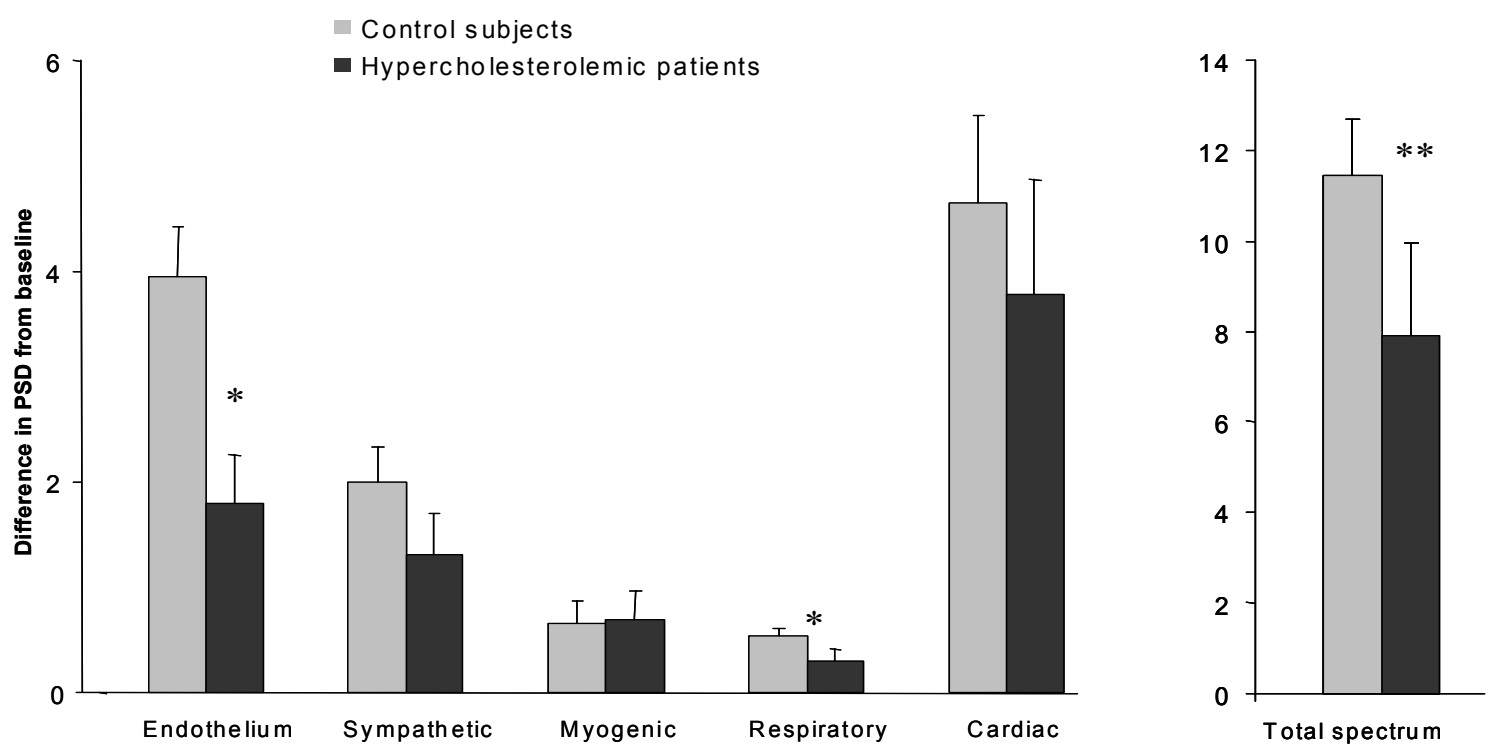

Fig. 1. Differences in power spectral density $\left(\mathrm{PU}^{2} / \mathrm{Hz}\right)$ between acetylcholine iontophoresis and baseline (mean $\pm \mathrm{SEM}$ ) for each skin blood flowmotion subinterval considered, as well as for $0.01-1.6 \mathrm{~Hz}$ skin blood flowmotion total spectrum, observed in fifteen hypercholesterolemic patients (black histograms) and in fifteen control subjects (gray histograms). PSD - power spectral density, $* p<0.005$ between hypercholesterolemic patients and control subjects., $* * p<0.05$ between hypercholesterolemic patients and control subjects.

\section{Results}

Hypercholesterolemic patients versus control subjects

The skin blood flow values obtained in control subjects and in hypercholesterolemic patients are reported in the upper part of Table 2. There was no significant difference in skin blood flow under basal conditions between hypercholesterolemic patients and control subjects (25.6 \pm 11.6 PU vs. 19.9 \pm 12.3 PU). Following ACh or SNP iontophoresis there was a significant increase in skin blood flow both in control subjects and in hypercholesterolemic patients. Hypercholesterolemic patients and control subjects did not differ in percentage maximal skin hyperemic response to ACh iontophoresis ( $803 \pm 496 \%$ vs. $791 \pm 456 \%$ ) or to SNP iontophoresis (549 $\pm 222 \%$ vs. $671 \pm 367 \%$ ).

As concerned the results of SBF investigation, hypercholesterolemic patients and control subjects did not differ in baseline PSD of SBF total spectrum (3.44 $\pm 2.59 \mathrm{PU}^{2} / \mathrm{Hz}$ vs. $\left.4.54 \pm 2.45 \mathrm{PU}^{2} / \mathrm{Hz}\right)$ as well as in baseline PSD of endothelial-dependent $0.01-0.02 \mathrm{~Hz}$ subinterval $\left(0.83 \pm 0.59 \mathrm{PU}^{2} / \mathrm{Hz}\right.$ vs. $\left.1.12 \pm 0.55 \mathrm{PU}^{2} / \mathrm{Hz}\right)$, sympathetic-related $0.02-0.06 \mathrm{~Hz}$ subinterval $(0.91 \pm 0.69$ $\mathrm{PU}^{2} / \mathrm{Hz} \quad$ vs. $\left.\quad 1.02 \pm 0.47 \quad \mathrm{PU}^{2} / \mathrm{Hz}\right), \quad$ myogenic-related $0.06-0.2 \mathrm{~Hz}$ subinterval $\left(0.60 \pm 0.45 \mathrm{PU}^{2} / \mathrm{Hz}\right.$ vs. $1.11 \pm 1.06$ $\mathrm{PU}^{2} / \mathrm{Hz}$ ), respiration-related $0.2-0.6 \mathrm{~Hz}$ subinterval $\left(0.34 \pm 0.30 \mathrm{PU}^{2} / \mathrm{Hz}\right.$ vs. $\left.0.26 \pm 0.10 \mathrm{PU}^{2} / \mathrm{Hz}\right)$ and heart activity-related $0.6-1.6 \mathrm{~Hz}$ subinterval $\left(0.78 \pm 0.82 \mathrm{PU}^{2} / \mathrm{Hz}\right.$ vs. $\left.1.03 \pm 0.89 \mathrm{PU}^{2} / \mathrm{Hz}\right)$.

Following ACh iontophoresis, a significant increase in PSD of 0.01-1.6 Hz total spectrum, as well as in PSD of each of subinterval considered, was observed both in control subjects (from $\mathrm{p}<0.01$ to $\mathrm{p}<0.0001$ ) and in hypercholesterolemic patients (from $\mathrm{p}<0.05$ to $\mathrm{p}<0.005$ ). However, compared to control subjects, hypercholesterolemic patients showed a statistically significantly lower post-ACh iontophoresis increase in PSD of 0.01-1.6 total spectrum $\left(7.90 \pm 7.70 \mathrm{PU}^{2} / \mathrm{Hz}\right.$ vs. $\left.11.44 \pm 4.79 \mathrm{PU}^{2} / \mathrm{Hz}, \quad \mathrm{p}<0.05\right)$, as well as of the endothelial-dependent $\quad 0.01-0.02 \quad \mathrm{~Hz}$ subinterval $\left(1.80 \pm 1.73 \mathrm{PU}^{2} / \mathrm{Hz}\right.$ vs. $\left.3.59 \pm 1.78 \mathrm{PU}^{2} / \mathrm{Hz}, \mathrm{p}<0.005\right)$ and of the respiration related $0.2-0.6 \mathrm{~Hz}$ subinterval $\left(0.30 \pm 0.42 \mathrm{PU}^{2} / \mathrm{Hz}\right.$ vs. $\left.0.53 \pm 0.30 \quad \mathrm{PU}^{2} / \mathrm{Hz}, \mathrm{p}<0.005\right)$ (Fig. 1). No significant difference in post-ACh iontophoresis PSD increase of the other SBF subintervals considered was observed between hypercholesterolemic patients and control subjects (Fig. 1).

\section{Changes associated with rosuvastatin therapy in} hypercholesterolemic patients

Eleven hypercholesterolemic patients completed the 10 week period of rosuvastatin therapy and underwent post-therapy laboratory and LDF tests. Basal skin blood flow mean values and the maximal absolute or percentage hyperemic response to ACh or to SNP iontophoresis did not significantly change at the end of rosuvastatin therapy 

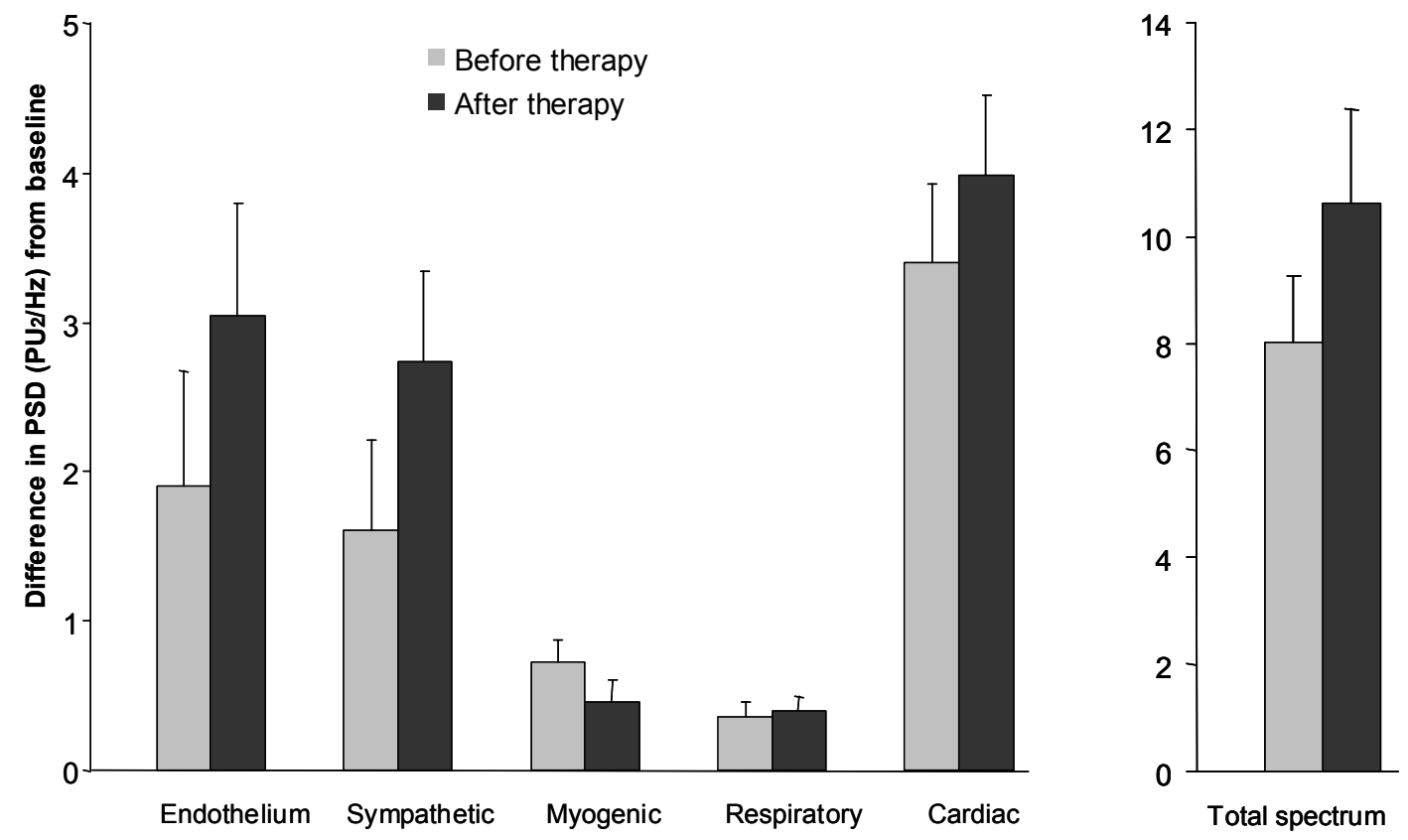

Fig. 2. Differences in power spectral density $\left(\mathrm{PU}^{2} / \mathrm{Hz}\right)$ between acetylcholine iontophoresis and baseline (mean $\pm \mathrm{SEM}$ ) for each skin blood flowmotion subinterval considered, as well as for 0.01-1.6 Hz skin blood flowmotion total spectrum, observed before (gray histograms) and after rosuvastatin (black histograms) therapy in eleven hypercholesterolemic patients.

Table 1. Clinical and laboratory features in the fifteen hypercholesterolemic patients and in fifteen control subjects.

\begin{tabular}{lll}
\hline $\begin{array}{l}\text { Clinical or laboratory } \\
\text { feature }\end{array}$ & $\begin{array}{l}\text { Control subjects } \\
(\mathbf{n}=\mathbf{1 5})\end{array}$ & $\begin{array}{l}\text { Hypercholesterolemic patients } \\
(\mathbf{n}=\mathbf{1 5})\end{array}$ \\
\hline Age (years) & $57 \pm 11$ & $59 \pm 10$ \\
Sex (M/F) & $5 / 10$ & $12 / 3$ \\
Body-mass index & $24.8 \pm 3.4$ & $26.2 \pm 3.3$ \\
Systolic blood pressure (mm Hg) & $126 \pm 13$ & $133 \pm 15$ \\
Diastolic blood pressure (mm Hg) & $77 \pm 6$ & $82 \pm 7 *$ \\
Total cholesterol (mmol/l) & $4.99 \pm 0.55$ & $6.90 \pm 1.24 * *$ \\
LDL cholesterol (mmol/l) & $2.72 \pm 0.65$ & $4.51 \pm 0.77 * *$ \\
LDH cholesterol (mmol/l) & $1.65 \pm 0.72$ & $1.44 \pm 0.24$ \\
Triglycerides (mmol/l) & $0.84 \pm 0.28$ & $2.43 \pm 2.51$ \\
Glucose (mmol/l) & $4.87 \pm 0.41$ & $5.19 \pm 0.85$ \\
\hline
\end{tabular}

Values are expressed as mean \pm S.D. $* \mathrm{p}<0.05, * * \mathrm{p}<0.005$

compared to before therapy in the eleven hypercholesterolemic patients (lower part of Table 2).

Table 3 shows the laboratory data observed before and at the end of rosuvastatin therapy in the same patients. A significantly lower total cholesterol $(p<0.0001)$ and LDL-cholesterol $(p<0.01)$ serum levels were observed at the end of rosuvastatin therapy compared to values before therapy. No significant change in HDL-cholesterol, triglycerides or glucose serum levels, as well as in diastolic or systolic blood pressure values were observed in the same patients at the end of rosuvastatin therapy compared to before therapy.

As concerned the results of SBF investigation, no significant difference in baseline PSD of 0.01-1.6 Hz total spectrum values was observed between before and after rosuvastatin therapy in the eleven hypercholesterolemic patients $(3.08 \pm 2.17$ vs. $4.86 \pm 3.59)$, as well as in baseline PSD of endothelial-dependent 0.01-0.02 Hz subinterval $\left(0.71 \pm 0.53 \mathrm{PU}^{2} / \mathrm{Hz}\right.$ vs. $\left.1.19 \pm 1.02 \mathrm{PU}^{2} / \mathrm{Hz}\right)$, sympathetic-related $0.02-0.06 \mathrm{~Hz}$ subinterval $(0.84 \pm 0.67$ 
Table 2. In the upper part of the table, basal skin blood flow values (mean \pm SD) and maximal skin blood flow values (mean \pm SD) following acetylcholine or sodium nitroprusside iontophoresis, observed in 15 hypercholesterolemic patients and 15 control subjects, are reported. Maximal skin blood flow percentage changes from baseline observed in the same two groups are also reported. In the lower part of the table, basal skin blood flow and maximal skin blood flow following acetylcholine or sodium nitroprusside iontophoresis, observed in 11 hypercholesterolemic patients before and after rosuvastatin therapy, are presented. Maximal percentage changes from baseline, observed before and after rosuvastatin therapy in the same patients, are also reported. The $p$ values in the table refer to the statistical difference between baseline and following acetylcholine or sodium nitroprusside iontophoresis.

\begin{tabular}{|c|c|c|c|c|c|c|}
\hline & $\begin{array}{l}\text { Basal } \\
\text { blood } \\
\text { flow (PU) }\end{array}$ & $\begin{array}{l}\text { Post-ACh } \\
\text { maximal } \\
\text { blood flow (PU) }\end{array}$ & $\begin{array}{l}\text { Post-ACh } \\
\text { change from } \\
\text { baseline }(\%)\end{array}$ & $\begin{array}{l}\text { Basal } \\
\text { blood flow } \\
(\mathrm{PU})\end{array}$ & $\begin{array}{l}\text { Post-SNP } \\
\text { maximal } \\
\text { blood flow (PU) }\end{array}$ & $\begin{array}{l}\text { Post-SNP } \\
\text { change from } \\
\text { baseline (\%) }\end{array}$ \\
\hline Control subjects & $25.6 \pm$ & $173.7 \pm 68.7$ & $803 \pm 496$ & $27.4 \pm 12.9$ & $139.3 \pm 67.0$ & $549 \pm 222$ \\
\hline$(n=15)$ & 11.6 & $\mathrm{p}<0.000001$ & & & $\mathrm{p}<0.000005$ & \\
\hline \multirow{3}{*}{$\begin{array}{l}\text { Hypercholesterolemic } \\
\text { patients }(n=15)\end{array}$} & $19.9 \pm 12.3$ & $131.2 \pm 86.7$ & $791 \pm 456$ & $22.0 \pm 12.1$ & $129.7 \pm 84.1$ & $671 \pm 367$ \\
\hline & & $\mathrm{p}<0.0005$ & & & $\mathrm{p}<0.0005$ & \\
\hline & $\begin{array}{l}\text { Basal } \\
\text { blood } \\
\text { flow (PU) }\end{array}$ & $\begin{array}{l}\text { Post-ACh } \\
\text { maximal } \\
\text { blood flow (PU) }\end{array}$ & $\begin{array}{l}\text { Post-ACh } \\
\text { change from } \\
\text { baseline }(\%)\end{array}$ & $\begin{array}{l}\text { Basal } \\
\text { blood flow } \\
\text { (PU) }\end{array}$ & $\begin{array}{l}\text { Post-SNP } \\
\text { maximal } \\
\text { blood flow (PU) }\end{array}$ & $\begin{array}{l}\text { Post-SNP } \\
\text { change from } \\
\text { baseline }(\%)\end{array}$ \\
\hline $\begin{array}{l}\text { Before rosuvastatin } \\
(n=11)\end{array}$ & $20.4 \pm 12.7$ & $\begin{array}{l}116.1 \pm 81.1 \\
\mathrm{p}<0.005\end{array}$ & $710 \pm 435$ & $23.5 \pm 12.6$ & $\begin{array}{l}150.3 \pm 88.9 \\
p<0.001\end{array}$ & $732 \pm 383$ \\
\hline $\begin{array}{l}\text { After rosuvastatin } \\
(n=11)\end{array}$ & $36.0 \pm 26.2$ & $\begin{array}{l}187.6 \pm 104.5 \\
\mathrm{p}<0.0005\end{array}$ & $602 \pm 193$ & $27.5 \pm 19.6$ & $\begin{array}{l}173.9 \pm 95.4 \\
p<0.0005\end{array}$ & $856 \pm 475$ \\
\hline
\end{tabular}

$\mathrm{PU}=$ perfusion unit, $\mathrm{ACh}=$ acetylcholine, $\mathrm{SNP}=$ sodium nitroprusside

Table 3. Laboratory parameters observed before and after rosuvastatin therapy in eleven hypercholesterolemic patients

\begin{tabular}{lll}
\hline & Before rosuvastatin & After rosuvastatin \\
\hline Total cholesterol $(\mathrm{mmol} / \mathrm{l})$ & $7.07 \pm 1.34$ & $4.96 \pm 1.08 *$ \\
LDL cholesterol $(\mathrm{mmol} / \mathrm{l})$ & $4.53 \pm 0.82$ & $2.94 \pm 0.89 * *$ \\
HDL cholesterol $(\mathrm{mmol} / \mathrm{l})$ & $1.47 \pm 0.24$ & $1.35 \pm 0.17$ \\
Triglycerides $(\mathrm{mmol} / \mathrm{l})$ & $2.75 \pm 2.86$ & $1.64 \pm 0.93$ \\
Glucose $(\mathrm{mmol} / \mathrm{l})$ & $5.31 \pm 0.87$ & $5.46 \pm 0.77$ \\
\hline
\end{tabular}

Data are mean \pm SD. $* p<0.0001, * * p<0.01$

$\mathrm{PU}^{2} / \mathrm{Hz}$ vs. $\left.1.16 \pm 0.98 \mathrm{PU}^{2} / \mathrm{Hz}\right)$, myogenic-related $0.06-$ $0.2 \mathrm{~Hz}$ subinterval $\left(0.53 \pm 0.37 \mathrm{PU}^{2} / \mathrm{Hz}\right.$ vs. $0.93 \pm 0.74$ $\mathrm{PU}^{2} / \mathrm{Hz}$ ), respiration-related $0.2-0.6 \mathrm{~Hz}$ subinterval $\left(0.26 \pm 0.14 \mathrm{PU}^{2} / \mathrm{Hz}\right.$ vs. $\left.0.38 \pm 0.29 \mathrm{PU}^{2} / \mathrm{Hz}\right)$ or heart activity-related $0.6-1.6 \mathrm{~Hz}$ subinterval $\left(0.74 \pm 0.76 \mathrm{PU}^{2} / \mathrm{Hz}\right.$ vs. $1.20 \pm 0.74 \mathrm{PU}^{2} / \mathrm{Hz}$ ). No significant change in postACh PSD increase from baseline (mean \pm SEM difference from baseline) was observed between values before and after rosuvastatin therapy for each of the SBF subintervals investigated, as well as for SBF total spectrum (Fig. 2). However, the change induced by rosuvastatin therapy in post-ACh PSD increase from baseline of the endothelial-dependent 0.01-0.02 Hz SBF subinterval was very near to the statistical significance (from 1.91 $\pm .94 \mathrm{PU}^{2} / \mathrm{Hz}$ to $3.04 \pm 2.85 \mathrm{PU}^{2} / \mathrm{Hz} ; \mathrm{p}=0.07$ ) (Fig. 2).

\section{Discussion}

To our knowledge, this is the first study which explored in hypercholesterolemic patients the LDF skin blood flowmotion, whose investigation has been 
proposed for evaluating the skin microvascular function in clinical setting (Kvernmo et al. 1999, Kvandal et al. 2003). We observed a blunted ACh-induced increase in the spectral amplitude of $0.01-0.02 \mathrm{~Hz}$ SBF component, known to be related to endothelial activity (Stefanovska et al. 1999, Kvernmo et al. 1999), in our hypercholesterolemic patients without clinically manifest arterial disease. The same patients also showed a blunted ACh-induced increase in spectral amplitude of the 0.011.6 Hz SBF total spectrum, as well as of the $0.2-0.6 \mathrm{~Hz}$ SBF component (known to be related to respiratory activity), while they did not differ from control subjects in the response to $\mathrm{ACh}$ of the other SBF components. Moreover, similarly to a previous study (Khan et al. 1999), our hypercholesterolemic patients without clinically manifest arterial disease exhibited a preserved skin vasodilator response to ACh and SNP iontophoresis.

The spectral amplitude increase of the 0.01-0.02 SBF $\mathrm{Hz}$ component in response to the endotheliumdependent vasodilator $\mathrm{ACh}$ has been shown to reflect the efficiency of skin microvascular endothelial function (Kvernmo et al. 1999, Kvandal et al. 2003). Therefore, our finding of a blunted ACh-induced spectral amplitude increase of the 0.01-0.02 Hz SBF component in hypercholesterolemic patients, could be an early sign of skin microvascular endothelial dysfunction in these patients. Considering the exclusion criteria, which we used for selecting hypercholesterolemic patients, such as arterial hypertension, smoke or diabetes, potentially able to induce skin microvascular endothelial dysfunction, this finding may be ascribed to the hypercholesterolemic condition.

Previous studies, based on LDF measurement of the skin vasodilator response to $\mathrm{ACh}$ and SNP iontophoresis, failed to clearly demonstrate endothelial dysfunction in the skin microvascular bed of hypercholesterolemic patients without manifest vascular disease (Khan et al. 1999). However, our finding of blunted ACh-induced increase of the endothelialdependent SBF component in hypercholesterolemic patients, in spite of a preserved skin vasodilator response to $\mathrm{ACh}$ in the same patients, suggests that SBF investigation is more sensitive in the study of skin endothelial function than the LDF measurement of skin blood flow response to $\mathrm{ACh}$. On the other hand, the study of the endothelial function in the skin microvascular bed is clinically important in hypercholesterolemic patients, taken into account that endothelial cell dysfunction is foremost a microvascular disease (Stewart et al. 2004) and that the investigation of the cutaneous microcirculation using LDF may adequately reflect the vascular involvement of other vascular beds, including cardiac muscle (Jung et al. 2001, Shamin-Uizzaman et al. 2002).

The blunted ACh-induced spectral amplitude increase of the $0.2-0.6 \mathrm{~Hz} \mathrm{SBF}$ component, related to respiratory activity, occurred in hypercholesterolemic patients without change in respiratory rate, suggesting that this finding was due to a reduced transmission to the skin microcirculation of the central hemodynamic modifications induced by respiration. Moreover, the blunted ACh-induced spectral increase of the SBF 0.01-1.6 Hz total spectrum could be only a secondary finding due to the blunted ACh-induced increase of the endothelial and respiration-related SBF components.

A second aim of our study was to evaluate possible changes in microvascular endothelial function associated to rosuvastatin therapy in our hypercholesterolemic patients.

Previous studies (Khan et al. 1999, Haak et al. 2001, Štulc et al. 2003), based on LDF measurement of skin vasodilator response to different stimuli, failed to clearly demonstrate a positive effect of statin therapy on skin microvascular endothelial function in hypercholesterolemic patients.

Fluvastatin therapy induced a significant increase in skin vasodilator response to SNP, but not to $\mathrm{ACh}$, in hypercholesterolemic patients with peripheral arterial obstructive disease (Khan et al. 1999), which is consistent only with an improvement of the skin endothelium-independent microvascular reactivity. A marginal improvement in the skin vasodilator response to thermal stimulus was observed in hypercholesterolemic patients after fluvastatin therapy (Haak et al. 2001). Moreover, no change in skin microvascular reactivity to ischemic or thermal stimuli was observed in hypercholesterolemic patients after atorvastatin therapy (Štulc et al. 2003).

Similarly to the study of Khan et al. (1999) we did not observe any significant increase in skin vasodilator response to $\mathrm{ACh}$ iontophoresis in our hypercholesterolemic patients after statin therapy. However, at the end of rosuvastatin therapy there was an ACh-induced spectral amplitude increase of the endothelial-related SBF component very near to the statistical significance compared to the pretreatment investigation, which could reflect the tendency to an improvement in skin endothelial function associated to 
rosuvastatin therapy. Further studies based on a controlled design and with a bigger number of patients are needed to clearly demonstrate a positive effect of rosuvastatin therapy on endothelial function in hypercholesterolemic patients.

A possible limitation of our study was the relatively small number of the studied subjects which could lower the power of the statistical analysis of our findings on SBF investigation. We did not perform any study on the SBF investigation reproducibility. However, in a previous study (Bernardi et al. 1997) the inter- and intra-day variation of the low-frequency or highfrequency SBF components was not higher than $15 \%$ or $13 \%$, respectively. These findings may give sufficient reliability to our statistical analysis. A possible source of misinterpretation of our findings in the study of SBF during ACh iontophoresis could arise from the instability of LDF signal during this procedure. However, the ACh iontophoresis protocol, we used in the present study, elicited a rapid and progressive increase of the laser Doppler signal amplitude beginning from the first iontophoretic pulses, followed by a stable laser Doppler signal. The absence of wide and rapid LDF tracing fluctuations following each ACh iontophoresis stimulation makes sufficiently reliable the results of the SBF spectral analysis investigation.

A possible caveat of this study was the prevalence of women among control subjects, while men were prevalent among hypercholesterolemic patients. However, the post-menopausal age of the recruited women in the control group may minimize this possible caveat. Another possible limitation of this study is the significantly higher diastolic blood pressure in hypercholesterolemic patients compared to control subjects. However, no hypercholesterolemic patient exceeded the normal values of arterial blood pressure.

In conclusion, our study in hypercholesterolemic patients without clinically manifest arterial diseases showed a blunted AChinduced increase in spectral amplitude of 0.01-0.02 Hz endothelium related SBF component, which could be an early sign of skin endothelial dysfunction in these patients. A preserved skin vasodilator response to ACh or to SNP was also observed in the same patients. After rosuvastatin therapy there was an ACh-induced spectral amplitude increase of the endothelium-related SBF component very near to the statistical significance, which could reflect the tendency to an improvement in skin endothelial function by rosuvastatin therapy. The assessment of SBF by spectral analysis of skin LDF signal seems to be a promising method for implementing the efficacy of conventional LDF tests in investigating skin microvascular endothelial function in clinical setting.

\section{Conflict of Interest}

There is no conflict of interest.

\section{Acknowledgements}

Department of Internal Medicine of Pisa University give the grant support for this study.

\section{References}

BERNARDI 1, ROSSI M, LEUZZI S, MEVIO E, FORNASARI G, CALCIATI A, ORLANDI C, FRATINO P: Reduction of $0.1 \mathrm{~Hz}$ microcirculatory fluctuations as evidence of sympathetic dysfunction in insulin-dependent diabetes. Cardiovasc Res 34: 185-191, 1997.

BINGGELI C, SPIEKER LE, CORTI R, SUDANO I, STOJANOVIC V, HAYOZ D, LUSCHER TF, NOLL G: Statins enhance post-ischemic hyperemia in the skin circulation of hypercholesterolemic patients: a monitoring test of endothelial dysfunction for clinical practice? J Am Coll Cardiol 42: 71-77, 2003.

BOLLINGER A, YANAR A, HOFFMAN U, FRANZECK UK: Is high frequency fluxmotion due to respiration or to vasomotion activity? In: Progress in Applied Microcirculation. K MESSMER (ed), Karger, Basel, 1993, pp $52-55$.

COLANTUONI A, BERTUGLIA S, INTAGLIETTA M: Microvascular vasomotion: origin of laser Doppler fluxmotion. Int J Microcirc Clin Exp 14: 151-158, 1994.

COLANTUONI A, BERTUGLIA S, INTAGLIETTA M: Quantitation of rhythmic diameter changes in arterial microcirculation. Am J Physiol 246: H508-H517, 1984.

DAVIGNON J, GANZ P: Role of endothelial dysfunction in atherosclerosis. Circulation 109: 27-32, 2004. 
HAAK E, ABLETSHAUSER C, WEBER S, GOEDICKE C, MARTIN N, HERMANNS N, LACKNER K, KUSTERER K, USADEL KH, HAAK T: Fluvastatin therapy improves microcirculation in patients with hyperlipidemia. Atherosclerosis 155: 395-401, 2001.

JUNG F, MROWIETZ C, LABARRERE C: Primary cutaneous microangiopathy in heart recipients. Microvasc Res 62: 154-163, 2001.

KHAN F, LITCHFIELD SJ, STONEBRIDGE PA, BELCH JJF: Lipid-lowering and skin vascular responses in patients with hypercholesterolaemia and peripheral arterial obstructive disease. Vasc Med 4: 233-238, 1999.

KVANDAL P, STEFANOVSKA A, VEBER M, KVERMMO HD, KIRKEBOEN KA: Regulation of human cutaneous circulation evaluated by laser Doppler flowmetry, iontophoresis, and spectral analysis: importance of nitric oxide and prostaglandines. Microvasc Res 65: 160-171, 2003.

KVERNMO HD, STEFANOVSKA A, KIRKEBOEN KA, KVERNEBO K: Oscillations in the human cutaneous blood perfusion signal modified by endothelium-dependent and endothelium-independent vasodilators. Microvasc Res 57: 298-309, 1999.

MANNINEN V, TENKANEN L, KOSKINEN P,HUTTUNEN JK, MÄNTÄRRI M, HEINONEN OP, FRICK MH: Joint effects of serum triglyceride and LDL cholesterol concentration on coronary heart disease risk in the Helsinki Heart study: implications for treatment. Circulation 85: 37-45, 1992.

MORRIS SJ, SHORE AC, TOOKE JE: Responses of the skin microcirculation to acetylcholine and sodium nitroprusside in patients with NIDDM. Diabetologia 38: 1337-1344, 1995.

ROSSI M, CARPI A, DI MARIA C, GALETTA F, SANTORO G: Spectral analysis of laser Doppler skin blood flow oscillations in human essential arterial hypertension. Microvasc Res 72: 34-41, 2006.

ROSSI M, RICCO R, CARPI A: Spectral analysis of skin laser Doppler blood perfusion signal during cutaneous hyperemia in response to acetylcholine iontophoresis and ischemia in normal subjects. Clin Hemorheol Microcirc 31: 303-310, 2004.

SERNÉ EH, IJEZERMAN RG, GANS RO, NIJVELDT R, DE VRIES G, EVERTZ R, DONKER JM, STEHOUWER CD: Direct evidence for insulin-induced capillary recruitment in skin of healthy subjects during physiological hyperinsulinemia. Diabetes 51: 1515-1522, 2002.

SHAMIM-UIZZAMAN Q, PFENNINGER D, KEHRER C: Altered cutaneous microvascular responses to reactive hyperemia in coronary artery disease: a comparative study with conduit vessel responses. Clin Sci 103: 267273, 2002.

STAUSS HM, ANDERSON EA, HAYNES WG, KREGEL KC: Frequency response characteristics of sympathetically mediated vasomotor waves in humans. Am J Physiol 274: H1277-H1283, 1998.

STEFANOVSKA A, KROSELJ P: Correlation integral and frequency analysis of cardiovascular functions. Open Syst Inf Dyn 4: 457-478, 1997.

STEFANOVSKA A, BRACIC M, KVERNMO K: Wavelet analysis of oscillations in the peripheral blood circulation measured by laser Doppler technique. IEEE Trans Biomed Eng 46: 1230-1239, 1999.

STEIN JH, CARLSSON CM, PAPCKEBENSON K, AESCHELIMANN SE, BODEMER A, CARNES M, MCBRIDE PE: The effects of lipid-lowering and antioxidant vitamin therapies on flow-mediated vasodilation of the brachial artery in older adults with hypercholesterolemia. J Am Coll Cardiol 38: 1806-1813, 2001.

STEWART J, KOHEN A, BROUDER D, RAHIM F, ADLER S, GARRICK R, GOLIGORSKY M: Noninvasive interrogation of microvasculature forr signs of endothelial dysfunction in patients with chronic renal failure. Am J Physiol 287: H2687-H2696, 2004.

ŠTULC T, KASALOVÁ Z, PRÁZNÝ M, VRÁBLÍK M, ŠKRHA J, ČEŠKA R: Microvascular reactivity in patients with hypercholesterolemia: effect of lipid lowering treatment: effect of lipid lowering treatment. Physiol Res 52: 439-445, 2003.

VOGEL RA: Cholesterol lowering and endothelial function. Am J Med 107: 479-487, 1999. 